\title{
Participação social nos processos de criação e gestão da Reserva Extrativista Marinha de Tracuateua - PA, Brasil
}

\section{Social participation in the creation and management processes of the Marine Extractive Reserve of Tracuateua - PA, Brazil}

Thaylana Pires do Nascimento - Mestranda em Ciências Ambientais, pelo Programa de Pós-Graduação em Ciências Ambientais da Universidade Federal do Pará(PPGCA/ UFPA). E-mail: thaylana.tata@gmail.com

Josinaldo Reis do Nascimento - Doutorando em Geografia Humana, pelo Programa de Pós-Graduação em Geografia Humana da Universidade de São Paulo (PPGH/USP). Professor do Instituto Federal de Educação, Ciência e Tecnologia do Pará (IFPA). E-mail: josinaldoreis@yahoo.com.br

\section{Resumo}

Esse trabalho realizou uma investigação sociológica acerca da participação das populações tradicionais da RESEX Marinha de Tracuateua- PA, nos processos de criação e gestão, considerando um recorte temporal de 19 anos. A história de vida e as entrevistas em profundidade, realizadas com os principais atores envolvidos nos processos investigados, durante o período de janeiro 2015 a junho de 2018, subsidiaram esta compreessão. A RESEX Tracuateua criada em 2005 é fruto de longos debates e mobilizações a partir do ano de 1998, como parte de uma das estratégias usadas por técnicos do CNPT/ IBAMA, e dos pescadores do litoral paraense para garantir o uso sustentável dos recursos naturais, bem como conter a expansão da carcinicultura. Passados 15 anos de sua criação, os fatos que motivaram os pescadores e as pescadoras do município a participarem dos processos de criação ainda estão bem vivos e cheios de ressignificados para os dias atuais.

\section{Palavra-chave}

Participação. Populações Tradicionais. Reserva Extrativista Marinha. Manguezal. Pesca Artesanal.

\begin{abstract}
This work carried out a sociological investigation about the participation of the traditional RESEX Marinha de Tracuateua - PA populations in creation and management processes, considering a time frame of 19 years. The life history and in-depth interviews conducted with the main subjects involved in the processes investigated during the period from January 2015 to June 2018, provides the base of this understanding. The Tracuateua RESEX, created in 2005, is the result of long discussions and mobilizations beginning in 1998, as part of one of the strategies used by CNPT / IBAMA technicians and fishermen from the coast of Pará to ensure the sustainable use of natural resources, and to contain the expansion of shrimp farming. 15 years after its creation, the facts that motivated the fishermen and fishermen of the municipality to participate in the breeding processes are still very alive and re-signified to the present day.
\end{abstract}

\section{Keywords}

Participation. Traditional Populations. Marine Extractive Reserve. Mangrove. Artisanal Fishing. 


\section{INTRODUÇÃO}

Os habitantes da floresta - seringueiros, castanheiros, ribeirinhos - povos extrativistas, são peculiares sociais e historicamente vivendo há mais de um século subordinados a relações quase servis de trabalho, criando seus filhos durante gerações em um mesmo espaço da floresta amazônica, extraindo o látex da seringueira e a castanha da castanheira sem ter precisado para isso abrir mais do que pequenas clareiras na mata -, são eles que hoje lutam pela concretização das Reservas Extrativistas, uma proposta de exploração racional para preservação da floresta (ALLEGRETTTI, 1989, p.23).

Com esta apresentação pública sobre os "povos da floresta”, a jovem antropóloga e ambientalista Mary Helena Allegretti, então presidente do Instituto de Estudos Amazônicos, abre a edição do terceiro volume da revista científica São Paulo em Perspectivas.

A revista se propunha, naquele momento, a fomentar um debate que já repercutia mundo afora sobre Ecologia e Meio Ambiente. No artigo intitulado Reservas Extrativistas: uma proposta para o desenvolvimento para floresta amazônica, a autora expõe os fatos com uma riqueza ímpar de detalhes, em uma narrativa viva, emocionante, quase que em tom de clemência, a fim colocar luz às problemáticas social, econômica e ambiental, travadas em lutas de forma contínua e sistemática, há mais de uma década, pelos povos extrativistas da Amazônia:"são eles também que, a partir da década de 70 [1970], que todos os anos, levantam-se contra o desmatamento, num movimento social denominado empate ${ }^{1}$, inédito e desconhecido tanto por parte dos pesquisadores quanto do grande público" (ALLEGRETTI, 1989, p.23).

Estes conflitos socioambientais ${ }^{2}$ na Amazônia, aos qual a autora se refere, foram intensificados na década de 1960 e só aumentaram a partir do Plano de Integração Nacional (PIN) e do I e II Plano Nacional de Desenvolvimento Econômico e Social (PND). Ao implantar um modelo de desenvolvimento de forma totalmente alheia às condições socioambientais locais, estes processos impulsionaram ainda mais os já elevados índices de concentração fundiária, resultando em sérios abalos aos modos de vida dos povos da floresta,

\footnotetext{
1 "Ações coletivas organizadas pelos seringueiros e coletores de castanha para impedir, ou 'empatar', o corte de árvores pelos fazendeiros nas áreas de extrativismo" (ALLEGRETTI, 2008, p. 42).

2 Para fins de compreensão, consideraremos conflitos socioambientais: "Disputas entre grupos sociais derivadas dos distintos tipos de relação que eles mantêm com seu meio natural" (LITTLE, 2001, p. 107).
} 
desarticulando sistemas sociais integrados e adaptados às condições da floresta tropical que vinham sendo reproduzidos há séculos de ocupação (ALLEGRETTTI, 2008; ALMEIDA, 2012).

Nesta conjuntura adversa, quando as primeiras Reservas Extrativistas (RESEX) foram criadas no Brasil, no final da década de 1980, o contexto político ainda era de fortes lutas por processos democráticos e de intensos conflitos socioambientais, sobretudo aqueles de natureza fundiária. Este contexto de embates culminou em outros eventos emblemáticos, como os brutais assassinatos dos líderes seringueiros: Wilson de Sousa Pinheiro e Francisco Mendes Filho, o Chico Mendes (ALMEIDA, 2004; ALLEGRET'TI, 2008).

Após estas perdas e conquistas dos povos da floresta, sucederam anos de intensos e calorosos debates com diversos setores da sociedade civil brasileira, universidades, movimentos sociais, ONG, políticos e ambientalistas, sob a coordenação dos ambientalistas e conservacionistas Maria Tereza Jorge Pádua e Maurício Mercadante. Foi apresentada uma minuta de lei ambiental para análise e aprovação do Conselho Nacional do Meio Ambiente (CONAMA). O órgão encaminhou o documento ao Legislativo, gerando diversas consultas públicas, responsáveis por enormes modificações no texto. "Entre os pontos mais polêmicos destacavam-se a questão das populações tradicionais, a participação popular no processo de criação e gestão de UC e as indenizações para desapropriações" (MEDEIROS, 2006, p.57).

Por isso, considerado uma importante conquista da legislação ambiental brasileira, o Sistema Nacional de Unidades de Conservação (SNUC), estabelecido por meio da Lei $\mathrm{n}^{\circ}$ 9.985, de 18 de julho de 2000, representou avanços nas diretrizes e procedimentos para criação, implantação e gestão de unidades de conservação das três esferas de governo, além das áreas particulares destinadas à conservação, devidamente reconhecidas pelo poder público (BRASIL, 2000).

As unidades de conservação integrantes do SNUC se dividem em dois grupos, com características específicas estabelecidas em seu Art. 7o: "I - Unidades de Proteção Integral; II - Unidades de Uso Sustentável”.

Compondo o segundo grupo, as Reservas Extrativistas (RESEX) se caracterizam como uma unidade de conservação de uso sustentável, pois se trata de uma área que é utilizada historicamente por populações tradicionais ${ }^{3}$.

\footnotetext{
Grupos culturalmente diferenciados e que se reconhecem como tais, que possuem formas próprias de organização social, que ocupam e usam territórios e recursos naturais como condição para sua reprodução cultural, social, religiosa, ancestral e econômica, utilizando conhecimentos, inovações e práticas gerados e transmitidos pela tradição (BRASIL, 2007, p. 1).
} 
De fato, o SNUC introduziu modificações importantes na política de criação e gestão de Unidades de Conservação (UC), sobretudo, aquelas de uso sustentável, que propôs e garantiu uma participação social ${ }^{4}$ mais efetiva das populações tradicionais nos processos decisórios dasUC em seus territórios ${ }^{5}$, como é o caso de instâncias decisórias importantes comoos Conselhos Deliberativos (CD), mesmo que velado e coordenado pelo braço estatal.

Vale ressaltar que nestes processos de participação devem ser "reconhecidos e valorizados os seus saberes, seus territórios e formas de organização social" (VIVACQUA; RODRIGUES, 2018, p. 394-395).

É nessa perspectiva que Sachs (2007) ressalta a importância de um Estado forte, que promova compatibilizações dos objetivos sociais, ambientais e econômicos em todos os níveis, e que articule arranjos institucionais entre os diferentes grupos sociais para construção de estratégias que garantam uma gestão eficiente de tais unidades. Contudo, independentemente de se ter o Estado como propulsor desta integração, “a participação social tem permeado tais realidades, seja com o aval do Estado ou não" (SIMONIAN, 2018, p. 123).

Nesse sentido, o presente estudo tem como objetivos: analisar os processos que motivaram a participação social dos pescadores e pescadoras artesanais do município de Tracuateua- PApara a criação da Reserva Extrativista Marinha,instituída em seus territórios tradicionais de pesca e de reprodução dos modos de vida;realizaruma reflexão acerca de suas estruturas organizacionaiscriadasa fim de atender às demandas impostas pela agenda da gestão compartilhada,advindasdaReserva Extrativista Marinha de Tracuateua (Mapa1).

\footnotetext{
4 A participação social, também conhecida como dos cidadãos, popular, democrática, comunitária, entre os muitos termos atualmente utilizados para referir-se à prática de inclusão dos cidadãos e dasorganizações da sociedade civilno processo decisório de algumas políticas públicas (MILANI, 2008, p. 554).

5 Para fins de compreensão neste estudo, analisamos o território "envolvendo, ao mesmo tempo, a dimensão espacial material das relações sociais e o conjunto de representações sobre o espaço ou 'imaginário geográfico' que não apenas move como integra ou é parte indissociável destas relações" (HAESBAERT, 2019, p.42).
} 
Mapa 1 - Localização da Reserva Extrativista Marinha de Tracuateuano contexto do estado do Pará

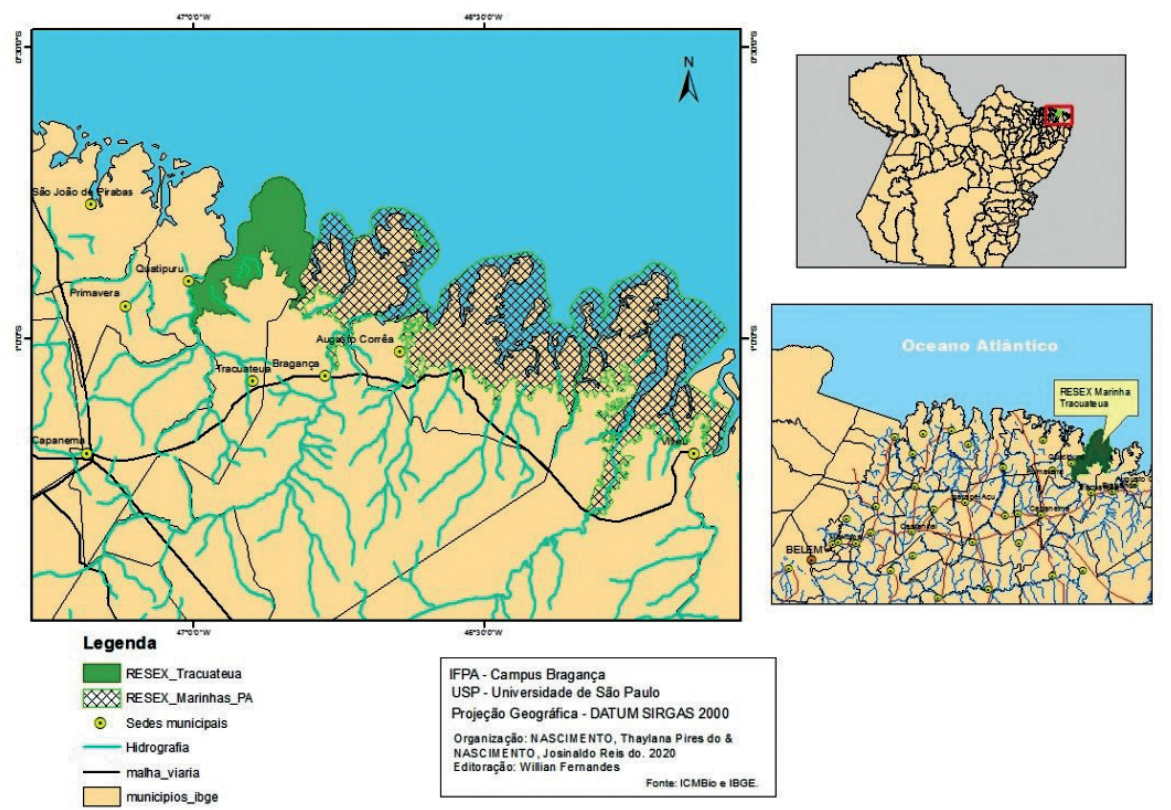

\section{RESERVA EXTRATIVISTA:CAMINHOS TRILHADOS POR CHICO,DO INTERIOR DA FLORESTA A BEIRA DO MAR}

Se descesse um enviado dos céus e garantisse que minha morte iria fortalecer nossa luta, até que valeria a pena. Mas a experiência nos ensina o contrário. Então, eu quero viver. Ato público e enterro numeroso não salvarão a Amazônia. Quero viver! (MARTINS, 1998, p. 28).

A epígrafe acima retrata uma fala do líder seringueiro Chico Mendes, dias antes de sua morte, em entrevista concedida ao jornalista Edilson Martins, do Jornal do Brasil ${ }^{6}$.É inegável reconhecer que,transcorridas mais de três décadas do assassinato de Chico Mendes, a concepção de reserva extrativista se fortaleceu e a efetivação de territórios de uso comum, aos moldes dos idealizados por ele e seus companheiros seringueiros no interior do Acre, transcendeu fronteiras para além

\footnotetext{
Os diretores do Jornal do Brasil (JB), do Rio de Janeiro, na época, Marcos Sá Corrêa e o Roberto Pompeu, se recusaram a publicar a entrevista alegando não apresentarem muita expressão os fatos e o personagem: "o redator-chefe do Jornal do Brasil achara que a entrevista não era uma história relevante o suficiente para ser publicada. Só teria valor - acrescentara o redator - se o entrevistado fosse assassinado" (MORO, 2011, p.405). "O Jornal do Brasil a publicou postumamente, no dia 24 de dezembro. Foi este depoimento, transformado em testamento, que injuriou o país e escandalizou o mundo" (MARTINS, 1998, p.21).
} 
do bioma amazônico, aportando em terras longínquas, até na beira do mar. Como também é verdadeira a afirmação de que: "a ausência de Chico transformou uma liderança forte, em muitas lideranças" (VENTURA, 2003, p. 226).

Mesmo sem mensagens vindas dos céus, o efeito transformador da presença de Chico Mendes no imaginário das lutas ambientais no Brasil e no mundo é incontestável.Os "povos da floresta", ao aliarem os discursos ambientalistas aos seus métodos tradicionais de manejo, seguindo seus próprios entendimentos de um sistema complexo, em meio a várias mudanças, embasam suas tradições e costumes estabelecidos historicamente, de forma que isso seja inserido, de algum modo, no direito agrário (ALMEIDA, 2004).

A partir desta concepção de território coletivo de uso comum, do reconhecimento social e político de suas populações, as Reservas Extrativistas representam um marco para o próprio Sistema Nacional de Unidade Conservação (SNUC). No entanto, ainda que marginal, à medida que se pressupõem a preservação da biodiversidade com a participação efetiva das comunidades e populações que historicamente a integram, elas foram, aos poucos, rompendo com as visões que, até então, eram alicerçadas no princípio do preservacionismo puro (DIEGUES, 2008).

Destas formas, rompendo estas barreiras, os preceitos construídos por Chico Mendes e seus companheiros, no interior da Amazônia, as RESEX surgem e se consolidam fundadas em uma territorialidade ${ }^{7}$ imbicada na identidade coletiva ${ }^{8}$ das populações tradicionais, como: seringueiros e coletores de castanhas, expandindo-se, posteriormente, às quebradeiras de coco babaçu, aos pescadores artesanais etc. (DUMITH, 2012).

Vale ressaltar que neste percurso recheado de lutas, no espaço e no tempo, Chico Mendes emprestou sua simplicidade e uma imortal e extraordinária força de penetração de suas ideias e dos seus companheiros, que sofreram adaptações ao longo destas décadas e, por vezes, em função das peculiaridades aonde estas chegaram, ganharam até sobrenome, como marinhas e/ou costeiras.

Porém, mais do que isto, é imprescindível reconhecer que sua essência permanece imutável. Como territórios de uso comum, o respeito aos saberestradicionais e o aprofundamento dos preceitos democráticos permanecem sendo os elementos basilares da concepção das reservas extrativistas.

\footnotetext{
Como o "conjunto de práticas sociais e os meios utilizados por distintos grupos sociais para se apropriar ou manter certo domínio (afetivo, cultural, político, econômico etc.) sobre/através de uma determinada parcela do espaço geográfico" (HAESBAERT; LIMONAD, 2007, p. 44).

8 O sentido de interação comum produzida por um dado número de pessoas (ou grupo) (MELUCCI, 1996).
} 
Por mais que novos arranjos institucionais venham se estabelecendo ao longo do tempo, sobretudo por parte do Estado, sob a justificativa de dinamizar os processos de gestão territorial, este modelo de unidade de conservação continua representando um importantíssimo contraponto aos modelos tradicionais de áreas protegidas, bem como nas formas de se conceber as relações entre o Estado e as populações tradicionais (ARAÚJO; NICOLAU, 2018; COSTA, 2018; PRADO; SEIXAS, 2018; PROST, 2018).

É sob o enfoque destes acontecimentos que os debates sobre as RESEX reverberaram longe, e chegam ao litoral de Santa Catarina, como nos conta Spínola (2011), e atingiram ainda o litoral amazônico, trazendo consigo reivindicações que têm contribuído igualmente para os processos contínuos de recomposição e reconfiguração dos territórios tradicionais de pesca e suas territorialidades (TEISSERENC; TEISSERENC, 2016).

Contudo, é importante frisar que as territorialidades presentes nas RESEX marinhas do litoral amazônico "se referem às formas tradicionais do uso dos recursos pesqueiros e de reprodução social, contudo, coexiste no território formas de reprodução capitalista, como a pesca industrial” (NASCIMENTO, 2019, p. 97).

São estes novos elementos que levaram Glasere Oliveira (2004) a intitularem as Reservas Extrativistas Marinhas como RESEX de "segunda geração", definição em que os contextos políticos, organizacionais e institucionais aparecem diferenciados das reservas extrativistas criadas em terras amazônicas no final da década de 1980.

O sentido ecológico, neste caso, é extrapolado e nota-se um sentido social diferente com inclusão de políticas públicas, como destacou Batista e Simonian (2013) no litoral paraense, bem como evidenciou Bucci (2009, p.20), ao debater o tema:

O caso das reservas extrativistas marinhas foi um outro momento deste reconhecimento, pois esses territórios não eram mais apenas constituídos de terras, mas também de águas - rios, lagos, mares, estuários - e a legislação nacional é frágil (ainda hoje) frente a estas novas questões de reconhecimento consuetudinário em territórios aquáticos. Por outro lado, os povos que vivem nestes locais definem, classificam e se representam nestes lugares com muita legitimidade e conhecimento sobre os complexos processos de pertencimento e reconhecimento destes territórios, pelos quais preservam suas (re) produções socioculturais, econômicas, políticas e ambientais, estabelecendo suas próprias formas de manutenção de natureza e cultura, ambiente e sociedade. 
Neste contexto, segundo Pradoe Seixas (2018), existem, no litoral brasileiro, 28 RESEX Marinha, das quais 12 destas unidades foram instituídas em territórios tradicionais de pesca no litoral do estado do Pará.

No entanto, é pertinente destacar, que a análise do território e suas territorialidades, "deve ser trabalhado sempre a partir de sua perspectiva temporal, já que envolve profundas transformações ao longo da história” (HAESBAERT; LIMONAD, 2007, p. 50).

Por isso, é imprescindível, no momento histórico da política ambiental brasileira, analisar o destaque de Nascimento (2019, p. 98), que alerta:

no momento histórico em questão, que a reprodução social dessas comunidades e populações tradicionais pesqueiras do litoral amazônico, encontra-se em risco, inclusive como outras para além do litoral amazônico. Tomemos um exemplo concreto: as quebradeiras de coco babaçu (Maranhão, Tocantins, Pará e Piauî), os quilombolas e indígenas do país, estas populações encontram-se historicamente ligadas pelas dificuldades de reconhecimento de direitos, cidadania, identidade e cultura, agora mais que nunca, com ascensão de um governo central de extrema direita (a partir das eleições de 2018), estaperspectiva do tempo na análise das territorialidades para populações tradicionais tornam-se cada vez mais relevante.

\section{TRAJETÓRIA METODOLÓGICA}

A trajetória metodológica de nossa análise sociológica foi alicerçada em pesquisas qualitativas, seguindo os preceitos propostos por Poupart (2008),compreendendo-a como um espaço de práticas relativamente diversificadas e múltiplas(POUPART, 2008), voltadas para o estudo de problemas sociais.

Como destacou Moraes (2005), para gerar análises sociológicas, antropológicas e políticas das questões ambientais é demandadoum trabalho de cunho teórico-metodológico diferenciado. Por isso, para atingir os objetivos propostos neste estudo, foi realizada uma grande articulação entre prática e teoria.

Neste sentido, o espaço de práticas foi o território da Reserva Extrativista Marinha de Tracuateua (Figura 1), uma unidade de conservaçãocriada oficialmente pelo Governo Federal,por meio do decreto s/nộpublicado no Diário Oficial da União,de 20 de maio de 2005. Atualmente, o território da RESEX Marinha de Tracuateua compreende uma área de 27.864,08 hectares, composto por 58 comunidades agropesqueiras do município homônimo, bem como a sede do município vizinho, Quatipuru e a Vila de Boa Vista, as quaiscompõem a zona de entorno da unidade. Esta estrutura organizacional está subdividida em 08 polos, de acordo com a Portaria no 83/2010/ICMBio. 
Os levantamentos de dados foram realizadados em sitações diversas (reuniões comunitárias, encontros, reuniões do conselho deliberativo e em conversas agendadas com lideranças)ao longo do período que compreende o início de 2015 a junho de 2018. Neste período foram feitos levantamentos da história de vida (HV) de 20 das principais lideranças envolvidos nos processos de criação e gestão da unidade de conservação (agentes públicos, líderes comunitários, religiosos, sindicais e políticos).

Seguindo os preceitos indicados por Bonie Quaresma (2005), em que a história de vida (HV) é abordada como uma entrevista em profundidade, na qual o pesquisador constantemente interage com o informante, com a principal função de retratar as experiências vivenciadas, tanto por pessoas como por grupos ou organizações. Estes autores observam, também, que existem dois tipos de histórias de vida: a completa, que retrata todo o conjunto da experiência vivida pelo interlocutor e a tópica (alvo desse estudo), que focaliza uma etapa ou um determinado período da experiência vivida pelo sujeito.

Dessa forma, para nosso estudo,as principais experiências dos nossos interlocultores foram os anos que antecederam a criação da RESEX Marinha de Tracuateua, buscando compreender o contexto político, economico e social, vistos a partir da ótica destes sujeitos, bem como os processos que os mobilizaram e motivaram a participar. Em quais etapas do processo participaram/participam? Como aconteceu esse primeiro momento de criação/ implementação da RESEX em Tracuateua?

Vale ressaltar que, segundo Brandão (2007), a história de um indivíduo particular é contada a partir da sua perspectiva, à luz da sua experiência, e está imbuída da subjetividade própria do narrador, cabendo ao investigador levar a cabo todas as informações presentes, para construir e/ou aferir a validade de uma teoria pré-existente, pois se trata de uma visão única, da própria experiência de vida do interlocutor.

Durante o período da pesquisa, além da observação participante, também foram analisadas teses e artigos científicos que aboradaram o tema, além de documentos e relatórios sobre a criação da RESEX Marinha de Tracuateua, disponíveis no site do Instituto Chico Mendes de Conservação da Biodiversidade (ICMBio); há ainda atas da fundação da Associação de Usuários da RESEX, bem como outros registros de reuniões do Conselho Deliberativo (CD).

Ainda com ointuito de vivenciar de forma mais presente os processos estudados, foram feitas participações nas reuniões do Conselho Deliberativo (CD) durante o período de estudo, além de participação em feiras, jornadas ambientais, oficinas e reuniões. Dessa forma, buscou-se construir diálogos e conhecimento que pudessem contribuir com o momento histórico estudado através dos depoimentos registrados aos longo do trabalho de campo. 


\section{RESULTADOS E DISCUSSÃO}

\subsection{PELA MARÉ DO MARAJÓ A TRACUATEUA.}

Louvada seja a maré que traz no ventre a flor da fé

da porção semente.

Só é pescador aquele que traz nas mãos o ofício do pescar, no coração, o sentido do compartilhar e na sua cabeça, a razão do conservar. (Nós Mangue, Waldemar Vergara L. Filho) ${ }^{9}$

"Louvada seja a maré" que trouxe de Soure a Tracuateua seus sopros de sustentabilidade e de luta pela conservação dos territórios tradicionais de pesca. Esta faixa litorânea, denominada de Costa Norte Brasileira, forma um ambiente de alta diversidade e produtividade pesqueira. Todavia, os esforços de captura nas proximidades da costa, propiciados principalmente pela pesca industrial, têm afetado negativamente os estoques pesqueiros (ISAACNAHUM; FERRARI, 2017).

Vale destacar que, em meio a esta alta diversidade e produtividade, a captura e a comercialização do caranguejo-uçá (Ucidescordatus) constitui um dos recursos mais importantes, sendo um dos componentes basilares da economia das populações que vivem nas proximidades desta linha de costa.

Considerada aimportância socioeconômica da cadeia produtiva do caranguejo-uçá, foi justamente no entorno de um conflito por invasão de áreas de captura deste crustáceo, que surgiram as primeiras discussões sobre RESEX Marinha no litoral paraense (ICMBIO, 2018). Tiradores de caranguejos, alguns membros da Associação dos Caranguejeiros de Soure, queixavam-se na delegacia local, de pescadores de outros municípios. Após constantes enfrentamentos com pescadores oriundos de São Caetano de Odivelas, município localizado no salgado paraense, sob a acusação de que estes estavam "invadindo" seus territórios

9 Nossos imensuráveis agradecimentos (inmemoriam) aoamigo e servidor público incansável, o sr.Waldemar Londres Vergara Filho (1958-2018),por fomentar ações que pudessem contribuir na mediação de conflitos socioambientais existentes em função do uso dos recursos pesqueiros nas Reservas Extrativistas dolitoral amazônico, bem como estimular a participação dos pescadores de maneira mais ativa nos processos de criação e gestão compartilhada das RESEX Marinhas do Pará, criando ambientes descontraídos para debates acerca das legislações pertinentes à pesca, aos povos eàs comunidades tradicionais. 
de pesca, fazendo uso de práticas de captura consideradas, pelos pescadores de Soure, como predatórias ${ }^{10}$ (laço, tapagem) ${ }^{11}$.

Neste contexto, outro elemento que não se pode deixar de fora da análise é que agestão da atividade pesqueira no Brasil, sobretudo da pesca artesanal de pequena escala, historicamente, é muito deficitária e com baixa participação das comunidades envolvidas (AMARAL; JABLONSKI, 2005; JIMENEZ et al., 2019). Conscientes disso, os tiradores de caranguejos de Soure, em 1996, reivindicavam a criação urgente de regulamentações que atendessem as necessidades da categoria e impedissem a atuação de tiradores de outros municípios.

No entanto, os conflitos se intensificaram, e em 1997, a representação destes pescadores pediu apoio e adesão de outras instituições (Pastoral Social, UFPA, Prefeitura Municipal, Colônia de Pescadores de Soure-PA) à sua causa. Desta forma, solicitaram formalmente junto à Superintendência do Instituto Brasileiro do Meio Ambiente e dos Recursos Naturais Renováveis (IBAMA/ PA),por meio do processo no 02018.003402/97-90, CNPT/1997, a criação de uma reserva extrativista. Em anexo a esta petição constava um abaixo-assinado com mais de 800 assinaturas.

Paralelamente, a tramitação do processo junto ao IBAMA e os conflitos por área de captura de caranguejo ainda ocorriam, e isso motivou a organização de evento na cidade de Soure, no ano de 1998, o "I Encontro de Manguezais de Soure". Nos debates, questões biológicas, aspectos geográficos, de ordenamento e aspectos socioeconômicos dos tiradores de caranguejos foram discutidos por pescadores, professores e órgãos públicos. Como resultado, um documento pedindo providências para a proteção da população e dos manguezais da região do Marajó foi enviado ao IBAMA.

Como consequência destas articulações frente a estes conflitos socioambientais em 2001, por meio do Decreto s/ $\mathrm{n}^{\circ}$ de 22 de novembro daquele ano, estava oficialmente instituída a Reserva Extrativista Marinha de Soure(BRASIL, 2001). Desta forma, tornando-se um modelo a ser seguido, uma vez que, naquele momento histórico, os discursos que reverberavam entre os

10 O "braceamento" é o método tradicional de captura do caranguejo-uçá permitido pela legislação. Na verdade, a única técnica considerada legal em todo litoral paraense. Este método consiste na inserção direta do braço na toca (ou galeria) visando extrair o caranguejo vivo para fora de seu habitat (PASSOS et al., 2016).

11 O laço é o método que consiste basicamente de uma armadilha confeccionada com um fio de nylon com um pequeno pedaço de madeira ou galho é posicionado na entrada das galerias (tocas), aprisionando o crustáceo no momento de sua saída para o forrageio. O tapa ou tapagem, técnica que consiste no bloqueio propriamente dito das galerias (tocas), com o sedimento do próprio mangue, obstruindo desta forma a entrada do ar e forçá-los a subir à superfície para respirar, neste momento são capturados (BATISTA; SIMONIAN, 2013). 
grupos de pescadores artesanais do litoral paraense deixavam claros os anseios destes trabalhadores em busca de um reconhecimento oficial de seus territórios, algo que fosse "exclusivo" para a pesca artesanal.

Sob a égide destas expectativas as mobilizações não cessaram, e no ano final do ano de 2002 o governo federal, entendendo as solicitações e os esforços dos pescadores artesanais, cria de uma única vez, mais 4 (quatro) Reservas Extrativistas Marinhas no litoral paraense ${ }^{12}$, sendo considerado um momento de vitória, principalmente pelas lideranças dos pescadores e pescadoras que encabeçaram as petições.

É importante ressaltar os diálogos entre as lideranças pesqueiras no litoral paraense que não findaram, ao contrário, os acontecimentos funcionavam com elemento motivador das demais organizações (Movimento dos Pescadores do Estado do Pará-MOPEPA; as associações comunitárias, os sindicatos de trabalhadores rurais) dos municípios vizinhos. É nesta constante construção histórica que mais 4 (quatro) ${ }^{13}$ RESEX Marinhas foram oficializadas via Decreto Presidencial s/nº, de 20 de maio de 2005, dentre essas, a RESEX Marinha de Tracuateua.

De acordo com as análises das entrevistas, percebemos que houve uma significativa inquietação por parte de técnicos do IBAMA, instituição responsável, na época, pelas criações destas UC; iniciativa esta que, em um primeiro momento, buscou conter a expansão da carcinicultura nos manguezais do litoral paraense (NASCIMENTO, 2019).

É neste contexto de fortes incertezas e conflitos socioambientais que se iniciam as mobilizações para a criação de novas reservas extrativistas no litoral paraense, através do projeto RESEX 2, financiado pelo Programa das Nações Unidas para o Desenvolvimento (PNUD).

As mobilizações que demandaram a criação das RESEX nos municípios de Tracuateua, Bragança, Augusto Corrêa e Viseu, iniciaram a partir do ano de 1998. Especificamente no município de Tracuateua, o processo de criação ocorreu através de grandes influências,impulsionadas por lideranças dos pescadores de Bragança. Processo esse, também iniciado no mesmo ano, através de mobilizações do Centro Nacional de Populações Tradicionais (CNPT/ IBAMA), por meio de palestras junto às populações locais, que mostravam a

12 A RESEX Marinha Mãe Grande de Curuçá, no município de Curuçá; em São João da Ponta e Maracanã, as RESEX Marinha que levavam o nome do município e a RESEX Marinha Chocoaré-Mato Grosso no município de Santarém Novo (BRASIL, 2002).

13 A RESEX Marinha Caeté-Taperaçu, localizada no município de Bragança; a RESEX Marinha Arai-Peroba o território do município de Augusto Correa; RESEX Marinha a Gurupi-Piriá e RESEX Marinha de Tracuateua, localizada no município homônimo (BRASIL, 2005). 
importância da conservação ambiental, os objetivos e desafios de uma reserva extrativista e como utilizá-la por meio de um instrumento de gestão do território por aquelas comunidades.

É interessante notar, aqui, o que Almeida (2004) denominou de Unidades de Mobilização ${ }^{14}$, pois essas unidades foram se estabelecendo em torno da ideia de RESEX em Tracuateua, cada qual a sua maneira, nos diferentes grupos sociais, e suas redes de relações sociais e políticas que nitidamente convergiam no sentido de reforçar a luta dos pescadores. Como destacou Nascimento (2019, p. 92) ao dissertar sobre o tema:

As ideias de os territórios de uso comum se difundiram na região, inicialmente através de uma articulação entre o Movimento dos Pescadores do Estado do Pará (MOPEPA) e Centro Nacional de Populações Tradicionais (CNPT/IBAMMA) e posteriormente com a Universidade Federal do Pará (UFPA), Empresa de Assistência Técnica e Extensão Rural do Estado do Pará (EMATER/PA), os Sindicatos dos Trabalhadores e Trabalhadoras Rurais (STTR) e Comissão Pastoral dos Pescadores (CPP).

É evidente que os processos que motivaram a participação social dos pescadores e pescadoras artesanais para criação da Reserva Extrativista Marinha de Tracuateua, contou com um forte apoio de organizações internas e de agentes externos. Nesse sentido, vale destacar que a conjuntura de Tracuateua, à época da gênese da unidade de conservação, não era muito diferente do encontrado por Souza, Coelho e Dias (2009) no Acre, pós-Chico Mendes. Estes autores destacam o papel da igreja católica nos processos organizacionais, orientando e formando seringueiros para os embates políticos do seu território.

No locus da nossa reflexão sociológica, o movimento sindical, especificamente o Sindicato dos Trabalhadores Rurais do município, configurase como agente estrutural importante na criação da RESEX no município.

O líder sindical Carlos Nazareno ainda está bastante vivo na memória coletiva dos nossos interlocutores, sendo reconhecido consonantemente como uma das lideranças que esteve na vanguarda do movimento pró-RESEX, e que contribuiu com a mobilização e orientação dos pescadores e pescadoras artesanais do município, na luta pela criação da UC, enfatizando sempre os desafios e as possibilidades concretas que poderiam ser oportunizadas a partir de diálogos abertos e francos nos processos de gestão compartilhada que eles irão enfrentar, tal como nos relatou uma liderança que contribuiu com a pesquisa:

14 Este conceito de Unidades de Mobilização refere-se à aglutinação de interesses específicos de grupos sociais não necessariamente homogêneos, que são aproximados circunstancialmente pelo poder nivelador da intervenção do Estado - por meio de políticas desenvolvimentistas, ambientais e agrárias -, ou das ações por ele incentivadas ou empreendidas, tais como as chamadas obras de infraestrutura (ALMEIDA, 2004, p.10). 
São todos meio vinculados à igreja, mas principalmente tem uma figura em Tracuateua que chamou e vinculou que era ligado ao Sindicato dos Trabalhadores Rurais, que era o Carlos Nazareno... Carlos Nazareno e o Sindicato dos Trabalhadores Rurais foram em Tracuateua e botaram a bandeira da RESEX nas suas pautas e foram passando em comunidade em comunidade. (Liderança, 62 anos. Entrevista concedida aos autoresem 11/11/2016, Bragança-PA.).

A partir dos dados que emergiram nas entrevistas, dentre os extrativistas de Tracuateua, muitos vislumbravam a criação de uma reserva no município, uma oportunidade de capitanear uma série de políticas públicas que poderiam advir com a criação da RESEX, por vezes, colocando o sentido ambiental vinculado a ela em segundo plano.

Decerto que, analisando os fatores motivacionais que culminaram com a criação da Reserva Extrativista Marinha de Tracuateua, pode-se afirmar que as demandas efetivas surgiram das populações das comunidades (Figura 2).

A partir dos fatos relatados, pode-se reconhecer aresiliência do conceito de Unidades de Mobilização, pois as lideranças das comunidades anteriormente citadas buscaram apoio junto a outras instituições e organizações (Prefeitura Municipal, Igreja Católica, Sindicato dos Trabalhadores Rurais), nas quais referendaram o abaixo-assinado produzido por eles e então enviado ao CNPT/ IBAMA, para assim compor o rito burocrático para solicitação da criação da Reserva Extrativista Marinha de Tracuateua em 2005.

Pelo exposto até aqui, é imprescindível olhar para os quase 15 anos já transcorridos desde sua criação e observar que há, em curso, diferentes processos de lutas pelo reconhecimento do território, que devem ser objeto de reflexão detida. Neste sentido, nossas interpretações não são descomprometidas e neutras, ao analisarmos os fatos que motivaram os grupos de pescadores e pescadoras artesanais do município de Tracuateua a participarem dos processos de criação da RESEX, observamos que estes ainda estão bem vivos e cheios de ressignificações, apontando agora para os desafios da gestão compartilhada e da conservação dos recursos naturais, dos quais eles dependem diretamente para reprodução dos seus modos de vida.

\subsection{A GENTE TOMA CONTA DO QUE É NOSSO: OS DESAFIOS DA GESTÃO COMPARTILHADA NA RESERVA EXTRATIVISTA MARINHA DE TRACUATEUA}

Cogestão ou Gestão Compartilhada: são acordos nos quais a comunidade local usuária do território e dos recursos naturais, o governo e outros atores sociais (agentes econômicos, agentes externos como ONGs, instituições 
acadêmicas e de pesquisa) repartem a responsabilidade e a autoridade de gerir o território e o uso dos seus recursos naturais (POMEROY; RIVERA-GUIEB, 2005, p.7-8).

Nesta conjuntura, a corresponsabilidade perpassa pela participação social efetiva dos usuários dos recursos naturais nas instâncias decisórias, fatores apontados como elementos primordiais para o sucesso deste modelo de gestão.

A essência deste modelo é uma tarefa desafiadora, em uma abordagem de propriedade comunal. Os processos de gestão compartilhada na pesca, principalmente a pesca de pequena escala, vêm sendo investigados em diversos países da África, Ásia, Europa e América do Norte. Os resultados mostram que o sucesso destas ações está diretamente relacionado à cultura política e aspirações dos usuários diretos dos recursos, bem como às maneiras que as instituições externas estão inseridas nas comunidades (SEN; NIELSEN, 1996; JENTOFT; MCCAY; WILSON, 1998; WEVER et al., 2012).

Partindo desses pressupostos, percebemos que a participação nos fóruns de gestão da RESEX Marinha de Tracuateua se dá de maneira representativa. Outrossim, poderemos buscar compreender como os extrativistas estão inseridos nos processos de gestão da Reserva Extrativista Marinha de Tracuateua, analisando os fatos desde da demanda por sua criação, implementação e nas demais instâncias decisórias.

Em última instância, o principal fórum é o conselho deliberativo, porém existem estruturas intermediárias, que são os comitês comunitários, isto é, pequenos coletivos de debates dos polos (5 pessoas), que funcionam como representações políticas dos extrativistas nas comunidades, sendo que destes coletivos saem as representações de base comunitária para o Conselho Deliberativo (CD) da RESEX. Aqui adaptados a fim de atender às peculiaridades locais:

No Pará, além de conquistas sociais adquiridas também através do Programa Nacional de Reforma Agrária e de parcerias com ONGs, nacionais ou estrangeiras, ressalta-se aqui as experiências de consolidação de organização comunitária, em particular as realizadas sob coordenação do funcionário do ICMBio, Waldemar Vergara Filho. No caso de Resex que abrangem dezenas de comunidades estendidas em vastas áreas não facilmente acessíveis entre elas, ou seja, quando o encontro regular de comunitários envolvidos na gestão territorial enfrentava dificuldades, o referido funcionário fomentou a criação de núcleos intermediários de reflexão sobre a Resex. Eles reúnem comunidades próximas em comitês de decisão com os representantes das comunidades, cada um composto dos dois conselheiros (do conselho deliberativo) e de mais três pessoas da comunidade - nãonecessariamente pescadoras - afim de pensar o manejo integrado dos recursos naturais (e não apenas pesqueiros), assim como 
os demais ofícios relacionados (como estaleiro) e atividades importantes para a vida social (como saúde e educação). A estrutura permite a descentralização de questões específicas, facilita o debate na copresença e envolve um número maior de pessoas, ampliando o exercício da democracia entre agentes diversos, mas pertencentes a uma mesma comunidade, e, portanto, tendo um destino comum (ao inverso do conselho deliberativo, que reúne agentes com interesses antagônicos e perspectivas muito distintas). A opção por essa estrutura age como fomento da autonomia da população envolvida (PROST, 2018, p. 329-330).

Waldemar Vergara Filhonão só estimulou a criação de novas estruturas organizacionais, como também estimulou a participação sociopolítica mais efetiva dos pescadores e pescadoras artesanais, e essas estruturas foram estimuladas e replicadas em quase todas as RESEX Marinhas do litoral.

Considerando as proposições estabelecidas no SNUC, logo após o decreto de criação da RESEX Marinha de Tracuateua, os pescadores e as pescadoras do território criaram a Associação dos Usuários da Reserva Extrativista Marinha de Tracuateua (AUREMAT). Organização que, desde então, vêm se configurando como o principal instrumento nos processos de cogestão da RESEX, e indo além, uma vez que a associação é uma organização coletiva criada para defender os interesses comuns dos extrativistas.

De acordo com o estatuto social da AUREMAT, a organização deve ter na formação de sua diretoria, representantes de cada categoria de extrativistas existentes no território da RESEX, como, por exemplo, caranguejeiros, pescadores, marisqueiros, entre outros, respeitando a composição por gênero de no mínimo 30\% de mulheres na sua direção.

Vale destacar que, na busca de atender de maneira mais real os anseios das comunidades, a AUREMAT optou em dividir as suas representatividades em polos, selecionados por proximidades e área de influência das comunidades mais populosas na qual orbitariam as comunidades de menores densidades populacionais. Sobre isso, uma liderança explica: "a gente chamou comunidade mais nucleada, Nanã, Tatu, Santa Helena, Flexeira, comunidade maior que agrupasse comunidades menores, que depois foram chamados de polos". (Liderança, 62 anos. Entrevista concedida aos autores em 17/11/2016, Belém-PA.).

Vê-se, desse modo, uma maneira de dinamizar os processos de cogestão. Desde o momento da criação da AUREMAT, o atual território da RESEX Marinha de Tracuateua foi dividido em 6 polos: Polo I) Quatipuru Mirim; Polo II) Flexeira; Polo III) Chapada; Polo IV) Santa Clara; Polo V) Santa Tereza; Polo VI) Cocal (Mapa 2). 
Mapa 2 - Localização das comunidades do entorno da Reserva Extrativista Marinha de Tracuateua, com destacando os Polos Comunitários

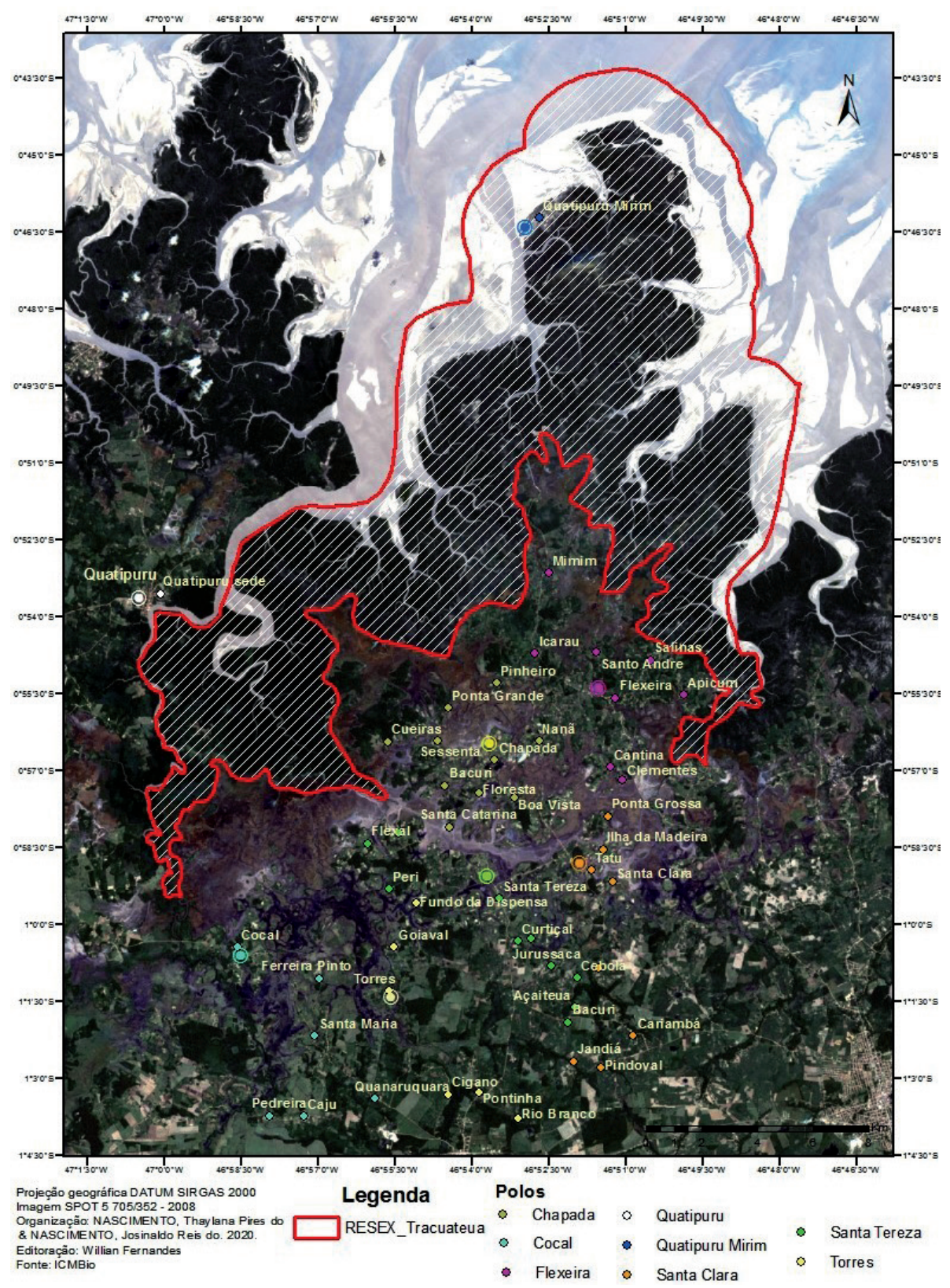

Contudo, atualizações mais recentes, em 2010, foram realizadas com intuito de atender às demandas de representações e participações que se sentiram alijadas do processo. Neste sentido, mais dois polos foram acrescidos, totalizando 
8 (oito) polos atualmente: a) Polo Santa Clara; b) Polo Torres; c) Polo Quatipuru Mirim; d) Polo Flexeira; e) Polo Cocal; f) Polo Chapada; g) Polo Santa Teresa;e h) Polo Quatipuru (Figura 1).

Figura 1 - Organograma da divisão representativa dos Polos comunitários da RESEX Marinha de Tracuateua

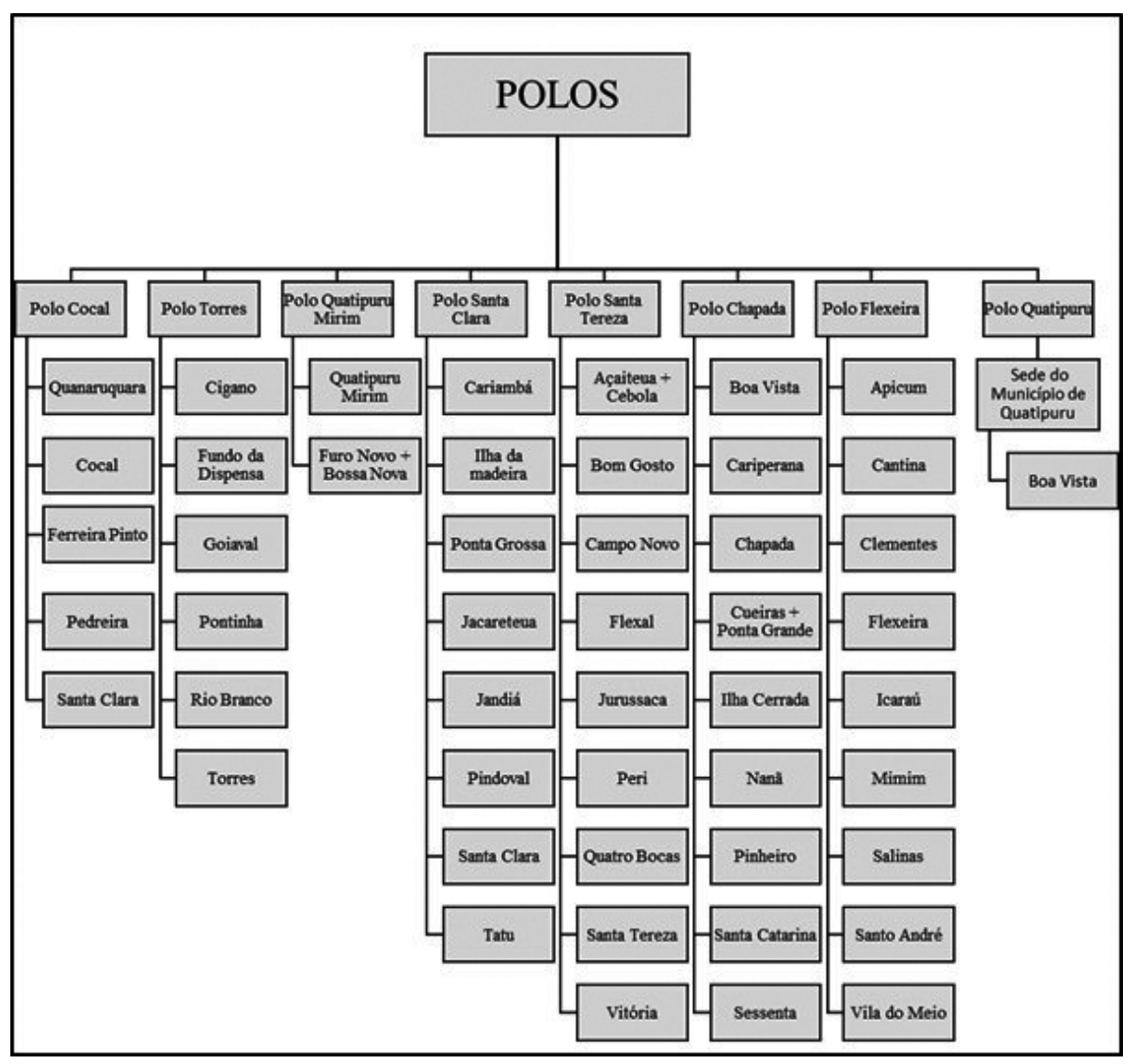

Fonte: os autores, 2017.

É importante destacar que a criação do Polo Quatipuru (h) foi uma estratégia proposta pelo gestor do ICMBio da época, provavelmente para evitar conflitos socioambientais e, desta forma, inserir os usuários da cidade de Quatipuru e seu distrito de Boa Vista, pois os mesmos fazem parte da mesma linha de manguezal que abrange a RESEX Marinha de Tracuateua.

Na comunidade do Nanã, distante $21 \mathrm{~km}$ da sede do município, encontrase a sede da AUREMAT, sendo essa comumente confundida pelas pessoas como sendo, de fato, a RESEX, quando é apenas a sede da representatividade dos extrativistas no processo de gestão compartilhada da UC. 
Em 2015, dados do Conselho Deliberativo (CD) estimaram que nos 08 polos comunitários da UC existe um número aproximado de 2.500 famílias na relação dos beneficiários (RB), contudo, em levantamentos feitos nesse mesmo ano e apresentados na reunião em questão, houve uma diminuição de forma considerável: cerca de 1.851 famílias foram encontradas nas comunidades. Provavelmente, tais diminuições ocorreram em função das mudanças metodológicas que definem a abrangência da zona de amortecimento.

Nos processos de gestão compartilhada, o conselho deliberativo é o órgão máximo na tomada de decisão nesta modalidade de unidade de conservação de uso sustentável, em que as discussões podem minimizar desacertos do passado. Atualmente, o conselho deliberativo da Reserva Extrativista Marinha de Tracuateua é presidido pelo representante institucional do ICMBio e composto por representantes de diversos órgãos públicos, pororganizações da sociedade civil e pelas representações das comunidades tradicionais da RESEX, que são efetivadas por meio de consulta, feita pelo presidente de cada polo, onde é escolhido o representante e seu suplente no conselho.

$\mathrm{Na}$ vizinha RESEX Marinha Caeté-Taperaçu, em Bragança, Silva Junior (2013), ao analisar o Conselho Deliberativo (CD), observou que os membros que o compõe são de diversas origens e formações, e os representantes das populações tradicionais são, majoritariamente, pescadores.

O Conselho Deliberativo (CD) dispõe de poderes decisórios sobre as questões relacionadas aos territórios, "e os representantes das populações tradicionais possuem maioria no mesmo (metade +1 ), conforme Instrução Normativa nº 2/2007, do ICMBio" (SANTOS; SCHIAVETTI, 2017, p. 482).

Neste contexto de representatividade, as associações de usuários exercem papéis fundamentais nos conselhos. Quando analisamos as formas de participação das Populações Tradicionais da RESEX Marinha de Tracuateua, nos seus processos de cogestão, destacamos a AUREMAT como a espinha dorsal da cogestão, por meio da qual essas populações têm acesso e voz ativa nas tomadas de decisões.

Embora a existência de um grande número de associados das modalidades supracitadas, a AUREMAT passou alguns períodos de dificuldades operacionais, como por exemplo, com o não pagamento das mensalidades oriundas dos sócios, a associação manteve-se operante muito em função de projetos, como o "Projeto Tracuateua: geração de renda, conservação ambiental e fortalecimento das organizações locais no Salgado Paraense"15, iniciado em março de

15 A proposta do projeto é contribuir para a melhoria das condições de vida das populações tradicionais mediantea difusão de atividades sustentáveis de geração de renda e da participação 
2013-2017. O Projeto Tracuateua não limitou suas ações apenas à RESEX Marinha de Tracuateua, buscou fortalecer as demais RESEX marinhas da região do salgado paraense. É importante destacar que um dos principais motivos para a seleção da AUREMAT para concorrer ao projeto foi a sua legalidade jurídica.

$\mathrm{Na}$ atual conjuntura, visualizando o final do projeto, os diretores da AUREMAT começaram fazer mobilizações por meiode reuniões nas comunidades, explicando a importância de se manter a associação ativa, fortalecendo laços entre eles, para que assim, possam ter uma entidade forte na defesa dos interesses dos associados e lutando por melhorias coletivas para as comunidades da RESEX. Contudo, para que isso ocorra, ressaltam seus diretores, é necessário que os associados estejam em dia com suas mensalidades para que desta forma possa funcionar de fato.

\section{À GUISA DE CONCLUSÃO}

É importante reviver os caminhos anteriores a este estudo, que perpassou pelas reservas extrativistas florestais e marinhas, até chegar a Tracuateua.Estas experiências de lutas, ora exitosas, ora traumáticas, decorrem construindo a história destes pescadores e pescadoras artesanais e suas formas características de se relacionar com espaço onde reproduzem seus modos de vida.

As criações de reservas extrativistas no litoral amazônico, entre estas, a de Tracuateua, configuram-se como resultantes de intensos embates sociais e mobilizações, desde o ano de 1998, das populações tradicionais e suas Unidades de Mobilização constituídas de diferentes modos em seu território. A institucionalização de seu território tradicional de pesca em RESEX Marinhas, de fato, estabeleceunovos marcos regulatórios para pesca artesanal e para conservação do ecossistema de manguezais desta faixa litorânea, o que visivelmente contribuiu para frear a expansão da carcinicultura para o litoral norte do Brasil e tem mantido um embate constante com forças externas e internas.

A criação da RESEX no município de Tracuateua foi fortemente influenciada por membros da igreja católica e lideranças sindicais, como Carlos Nazareno, do Sindicato dos Trabalhadores Rurais do município, e do ativista e servidor público, Waldemar Vergara Filho.

ativa das populações tradicionais na gestão de quatro Reservas Extrativistas da região do salgado, nordeste do estado do Pará. Para isso, propõe-se fortalecer as atividades de produção sustentável e da promoção do diálogo dos usuários das RESEX com o poder público e com os atores institucionais, visando um aprimoramento da governança (EUROPEAN COMMISSION, 2013). 
Os elementos justificadores que, inicialmente, para muitos pescadores,atrelavam-se diretamente a interesses pessoais, na concepção da maioria dos interlocutores que contribuíram com a pesquisa, mudaram completamente ao longo dos anos, o que repercutiu uma consciência ambiental bem mais coesa e que vem crescendo com o transcorrer de experiências que são frutos de uma série de lutas e sensibilizações nas comunidades, com reuniões, palestras e jornadas ambientais.

Atualmente, 12 (doze) é o total de RESEX marinhas ao longo do litoral paraense, o que corresponde a um território com 255.012,80 hectares de áreas protegidas, formando um verdadeiro cinturão de unidades de conservação de uso sustentável no litoral amazônico. É importante lembrar que uma parcela considerável deste território é composta pelo ecossistema manguezal, cuja área totaliza cerca de 148.984,50 hectares, garantindo, desta forma, o uso dos seus recursos para aproximadamente 309 comunidades pesqueiras, onde vivem algo próximo de 28.100 famílias, conforme destaca Isaac-Nahum (2013).

\section{REFERÊNCIAS}

ALLEGRETTI, M. H. Reservas Extrativistas: uma proposta de desenvolvimento da floresta amazônica. São Paulo em Perspectivas, São Paulo, v. 3, n. 4, p. 23 29, 1989.

ALLEGRETTI, M. H. A construção social de políticas públicas. Chico Mendes e o movimento dos seringueiros. Desenvolvimento e Meio Ambiente, Curitiba,v. 18, p. 39-59, 2008.

ALMEIDA, M. B. Direitos à floresta e ambientalismo: seringueiros e suas lutas. Revista Brasileira de Ciências Sociais, [S. l.], v. 19, n. 55, p. 33-53, 2004.

ALMEIDA, M. W. B. História ambiental e história social da Amazônia. In:AQUINO, T. T. V.(org.). Papo de Índio. Manaus: UEA Edições, 2012, v.12, p. 262-273.

AMARAL, A. C. Z.; JABLONSKI, S. Conservação da biodiversidade marinha e costeira no Brasil. MEGADIVERSIDADE, Belo Horizonte,v.1, n. 1, p.43-51, 2005.

ARAÚJO, V. P.; NICOLAU, O. S. Participação social na Reserva Extrativista Marinha de Arraial do Cabo: uma análise dos instrumentos de gestão sob a ótica da decolonialidade. Desenvolvimento e Meio Ambiente,Curitiba, v. 48, Edição especial: 30 Anos do Legado de Chico Mendes, v. 48, p. 299-320, 2018. 
BATISTA, I. M. S.; SIMONIAN, L. T. L. Implicações políticas, econômicas e socioambientais da RESEX Mãe Grande de Curuçá: perspectivas de desenvolvimento sustentável no estuário paraense? Novos Cadernos NAEA, Belém,v. 16, n. 1, p. 229-248, 2013.

BONI, V.; QUARESMA, S. J. Aprendendo a entrevistar: como fazer entrevistas em Ciências Sociais. Em Tese, Belo Horizonte,v. 2, n. 1, p. 68-80, 2005.

BRANDÃO, A. M. Entre a vida vivida e a vida contada: a história de vida como material primário de investigação sociológica. Configurações, Braga-PT, n. 3, p. 83-106, 2007.

BRASIL.Decreto $\mathbf{N}^{\mathbf{9}} \mathbf{9 . 3 8 4}$, de 22 de novembro de 2001. Cria a Reserva Extrativista Marinha de Soure [...].Brasília, DF: Presidência da República, [2001]. Disponível em: http://www.planalto.gov.br/ccivil_03/dnn/2001/Dnn9384. htm. Acesso em: 10 de mar. 2020.

BRASIL.Decreto $\mathbf{N}^{\mathbf{9}}$ 9.776, de 13 de dezembro de 2002.Cria a Reserva Extrativista Maracanã [...].Brasília, DF: Presidência da República, [2002]. Disponível em:http://www.planalto.gov.br/ccivil_03/dnn/2002/Dnn9776.htm. Acesso em: 4 mar. 2020.

BRASIL. Decreto Nº 6.040, de 7 de fevereiro de 2007. Institui a Política Nacional de Desenvolvimento Sustentável dos Povos e Comunidades Tradicionais.Diário Oficial da União: seção 1, Brasília, DF, n. 28, p. 316, quinta-feira, 08 de fevereiro de 2007.

BRASIL.Decreto de 20 de maio de 2005.Dispõe sobre a criação da Reserva Extrativista Marinha de Tracuateua, no Município de Tracuateua no Estado do Pará, e dá outras providências. Diário Oficial da União: seção 1, Brasília, DF, n. 97, p. 8, segunda-feira, 23 de maio de 2005.

BRASIL. Lei $\mathbf{N}^{\mathbf{0}} \mathbf{9 . 9 8 5}$, de18 de julhode 2000. Institui o Sistema Nacional de Unidades de Conservação da Natureza (SNUC).Brasília, DF: Presidência da República, [2000]. Disponível em: http://www.planalto.gov.br/ccivil_03/leis/ L9985.htm. Acesso em: 7 jan. 2018.

BRASIL. Portaria $\mathbf{N}^{\circ}$ 83, de 27 de agosto de 2010. Altera a composição do Conselho Deliberativo da Reserva Extrativista Marinha Tracuateua. Brasília, DF: ICMBio,[2010]. Disponível em: http://www.icmbio.gov.br/portal/images/ stories/docs-ucs/conselhos_consultivos/resex_marinha_tracateua.pdf. Acesso em: 29 jan. 2016. 


\section{BUCCI, T. M. Implementação da Reserva Extrativista Marinha do}

Corumbau-Ba: relações de atores e processos de mudanças. 2009. 116f. Tese (Doutorado em Desenvolvimento Regional e Meio Ambiente) - Programa de Pós-Graduação em Desenvolvimento Regional e Meio Ambiente, Universidade Estadual de Santa Cruz, Ilhéus, 2009.

COSTA, P. C. P. Reservas extrativistas marinhas: reflexões sobre desafios e oportunidades para a cogestão em áreas marinhas protegidas. Desenvolvimento e Meio Ambiente, Curitiba,v. 48, Edição especial: 30 Anos do Legado de Chico Mendes, p. 417-431, 2018.

DIEGUES, A. C. O mito moderno da natureza intocada. 6. ed. São Paulo: Hucitec; NUPAUB/USP, 2008. 198p.

DUMITH, R. C. A importância da gestão compartilhada e das áreas marinhas protegidas para o sistema socioecológico da pesca artesanal: o caso das reservas extrativistas marinhas. Geo'Textos, Salvador,v. 8, n. 2, p. 97-121, 2012.

EUROPEAN COMMISSION. InternationalCooperationandDevelopment: Projeto Tracuateua: geração de renda, conservação ambiental e fortalecimento das organizações locais no Salgado Paraense.EuropeanCommission, 2013. Disponível em: https://ec.europa.eu/europeaid/projects/projeto-tracuateuageracao-de-renda-conservacao-ambiental-e-fortalecimento-das-organizacoes_ pt. Acessoem: 24 jul. 2017.

GLASER, M.; OLIVEIRA, R. S. Prospects for the co-management of mangrove ecosystems on the North Brazilian coast: whose rights, whose duties and whose priorities? Natural ResourcesForum, [S. l.], v. 28, p. 224-233, 2004.

HAESBAERT, R. O mito da desterritorialização: do "fim dos territórios" à multiterritorialidade. 11. ed. Rio de Janeiro: Bertrand Brasil, 2019. 396p.

HAESBAERT, R.; LIMONAD, E. O território em tempos de globalização. Revista do Departamento de Geografia, Rio de Janeiro, v. 5, p. 7-19, 2007.

ICMBio. Caracterização da unidade reserva extrativista marinha de Tracuateua: Projeto PNUD BRA/08/002. Brasília: ICMBio, 2009. 127 p. Mimeografado.

ISAAC-NAHUM, V. J.Plano de gestão integrada dos recursos pesqueiros com enfoque ecossistêmico para as nove Reservas Extrativistas Marinhas do litoral paraense. Belém: UFPA, 2013 (Produto N. 4,Relatório final UFPA). 
ISAAC-NAHUM, V. J.; FERRARI, S. F. Assessment and management of the North Brazil Shelf Large Marine Ecosystem.Environmental Development, [ $S$. l.], v. 22, p.97-110, 2017.

JENTOFT, S.; MCCAY, B. J.; WILSON, D. C. Social theory and fisheries comanagement.Marine Policy, v. 22, n. 4, p. 423-436, 1998.

JIMENEZ, É. A.; BARBOZA, R. S. L.; AMARAL, M. T.; FRÉDOU, F. L. Understanding changes to fish stock abundance and associated conflicts: Perceptions of small-scale fishers from the Amazon coast of Brazil. Ocean\&Coastal Management, [S. l.], v. 182, p. 1-12, 2019.

LITTLE, P. E. Os conflitos socioambientais: um campo de estudo e de ação política. In: BURSZTYN, M. (org.). A difícil sustentabilidade: política energética e conflitos ambientais. Rio de Janeiro: Garamond, 2001.p. 107-122.

MARTINS, E. Chico Mendes: um povo da floresta. Rio de Janeiro: Garamond, 1998. 102p.

MEDEIROS, R. Evolução das tipologias e categorias de áreas protegidas no Brasil. Ambiente\&Sociedade, [S. l.],v. 9, n. 1, p. 41-64, 2006.

MELUCCI, A. Challenging codes: collective action in the information age. Cambridge: Cambridge University Press, 1996. 456p.

MILANI, C. R. S. O princípio da participação social na gestão de políticas públicas locais: uma análise de experiências latino-americanas e europeias. Revista de Administração Pública, São Paulo,v. 42, n. 3, p. 551-580, 2008.

MORAES, A. C. R. Meio ambiente e ciências humanas. 4. ed.São Paulo: Annablume, 2005. 161p.

MORO, J. Caminhos de liberdade: a luta pela defesa da selva. São Paulo:Editora Planeta Brasil, 2011. 460p.

NASCIMENTO, J. R. Resex marinha do litoral amazônico: territórios e territorialidades pesqueiros/Amazoncoast marine resex: territoriesandfishingterri torialities. Brazilian Journal of Development, v. 5, n. 12, p. 31686-31701, 2019.

PASSOS, P. H. S.; RIBEIRO, S. C. A.; BARBOSA, M. M. C.; VERGARA FILHO, W. L.Interação homem-natureza: os pescadores, os caranguejos e o Manguezal. Revista Caribeña de CienciasSociales, [S. l.], 2016.Disponível em: http:// www.eumed.net/rev/caribe/2016/04/manguezal.html. Acesso em: 30 mar. 2017. 
POMEROY, R.; RIVERA-GUIEB, R. Fisheryco-management: a practicalhandbook. Cambridge: CABI, 2005. 253p.

POUPART, J. A entrevista de tipo qualitativo: considerações epistemológicas, teóricas e metodológicas. In: POUPART, J.; DESLAURIERS, J.; GROULX, L.; LAPERRIERE, A.; MAYER, R.; PIRES, A. (org.). A pesquisa qualitativa: enfoques epistemológicos e metodológicos.Petrópolis: Vozes,2008.p. 215-253.

PRADO, D. S.; SEIXAS, C. S. Da floresta ao litoral: instrumentos de cogestão e o legado institucional das Reservas Extrativistas. Desenvolvimento e Meio Ambiente, Curitiba,v. 48, Edição especial: 30 Anos do Legado de Chico Mendes, p. 281-298, 2018.

PROST, C. Reservas extrativistas marinhas: avanço ou retrocesso? Desenvolvimento e Meio Ambiente, Curitiba,v. 48, Edição especial: 30 Anos do Legado de Chico Mendes, v. 48, p. 321-342, 2018.

SACHS, I. Primeiras intervenções. In: BECKER, B. K. (org.). Dilemas e desafios do desenvolvimento sustentável no Brasil. Rio de Janeiro: Garamond, 2007.p. 21-41.

SANTOS, C. Z.; SCHIAVETTTI, A. Reservas extrativistas marinhas do Brasil: contradições de ordem legal, sustentabilidade e aspecto ecológico. Boletim do Instituto de Pesca,São Paulo, v. 39, n. 4, p. 479-494, 2017.

SEN, S.; NIELSEN, J. R. Fisheries co-management: a comparative analysis. Marine policy, [S. l.],v. 20, n. 5, p. 405-418, 1996.

SILVA JUNIOR, S. R. Participação e relações de poder no Conselho Deliberativo da Reserva Extrativista Marinha de Caeté-Taperaçu, Bragança-PA.2013. 129f. Tese (Doutorado em Ciências Sociais) - Programa de Pós-Graduação em Ciências Sociais, Universidade Federal do Pará, Belém, 2013.

SIMONIAN, L. T. L. Políticas públicas e participação social nas Reservas Extrativistas amazônicas: entre avanços, limitações e Possibilidades. Desenvolvimento e Meio Ambiente, Curitiba,v. 48, Edição especial: 30 Anos do Legado de Chico Mendes, v. 48, p. 118-139, 2018.

SOUZA, G. E. A. B.; COELHO, F. M. G.; DIAS, M. M. Movimentos Sociais dos Seringueiros e a RESEX Chico Mendes: a cada conquista persiste a necessidade das lutas. In: CONGRESSO DA SOCIEDADE BRASILEIRA DE ECONOMIA, ADMINISTRAÇÃO E SOCIOLOGIA RURAL-SOBER, 47.,2009, Porto Alegre.Anais [...]. Porto Alegre: UFRGS, 2009. p. 1-18. 
SPINOLA, J. L. Participação e deliberação na Resex Marinha do Pirajubaé (SC). 2011, 207f. Tese (Doutorado Interdisciplinar em Meio Ambiente e Desenvolvimento) - Programa de Pós-Graduação em Meio Ambiente e Desenvolvimento,Universidade Federal do Paraná, Curitiba, 2011.

TEISSERENC, M. J. A.; TEISSERENC,P.Dinâmicas territoriais e socioeconômicas na Amazônia brasileira. In: TEISSERENC, M. J. A.; SANT'ANA JÚNIOR, H. A.; ESTERCI, N. (org.). Territórios, mobilizações e conservação socioambiental.São Luís: EDUFMA, 2016.p.31-60.

VENTURA, Z. Chico Mendes - Crime e castigo. São Paulo: Companhia, das Letras, 2003. 241p.

VIVACQUA, M.; RODRIGUES, H. C. L. Reservas Extrativistas Marinhas à luz da representação social de pescadores artesanais do litoral centro-sul de Santa Catarina. Desenvolvimento e Meio Ambiente, Curitiba,v. 48, Edição especial: 30 Anos do Legado de Chico Mendes, v. 48, p. 392-416, 2018.

WEVER, L.; GLASER, M.; GORRIS, P.; FERROL-SCHULTE, D. Decentralization and participation in integrated coastal management: Policy lessons from Brazil and Indonesia. Ocean \& coastal management, [S. l.],v. 66, p. 63-72, 2012. 